\title{
Focal Treatment on Prostate Cancer: The 3 Dilemmas Debating Focal Therapy for Prostate Cancer
}

\author{
Leiva Centeno J, Uriburu-Pizarro F* \\ Department of Urology, Sanatorio Allende Cordoba, Argentine
}

*Corresponding author: Uriburu Pizarro Facundo, Department of Urology, Sanatorio Allende, Cordoba, 3431 Fader Avenue, CerrodelasRosas, Argentine

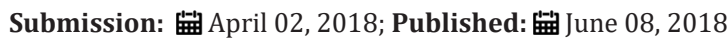

\begin{abstract}
Summary
The new technologies development and their application as alternatives in the therapeutic approach of Prostate Cancer, is still under discussion. We face an scenario that is more frequent day by day. However, it is required more time and more medicine based evidence, to understand if this concepts will turn off or turn on the lights on those impetuous affirmations with "truths" intentions.
\end{abstract}

Keywords: prostate cancer; Focal therapy; Prostate MRI.

\section{Introduction}

The pendulum that mobilized therapeutic options from radical prostatectomy to active surveillance, hosted in its oscillation place for a new modality, Focal Therapies (FT). By definition it is that treatment towards a specific focus (directed ablation) or towards a delimited area (ablation by quadrant, or hemiglandular or mixed). It was criticized since its beginnings and it have many detractors until today. Despite the new concepts evolution and the recent evidence, it have generated a new level of discussion. Its use is no longer questioned but rather the "For whom?" seeking to avoid over treatment and reach oncological disease control [1]. FT appears as a curative alternative to an organ-confined disease with the intention to preserve the quality of life and avoiding side effects, conserving oncological results (Figure 1).
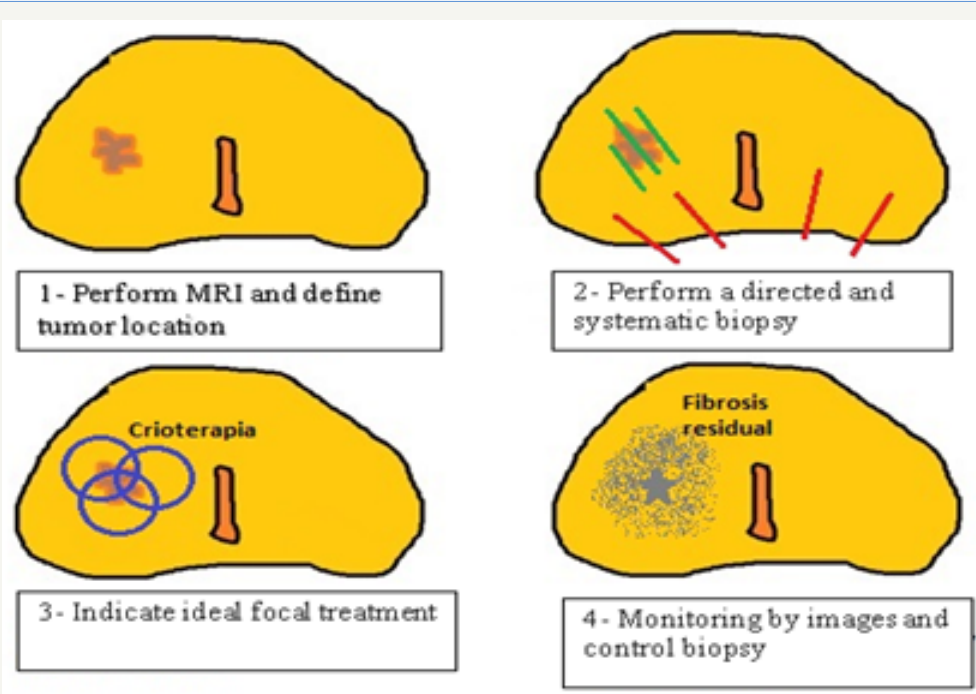

Figure 1: Structure model of a focal treatment (in this case, the Cryotherapy treatment area was graphed in image 3 , and residual fibrosis in image 4). 


\section{The first dilemma: Multifocal Disease}

In prostate cancer, multifocality as an usual presentation form was always the cornerstone against partial / focal treatment modalities [2]. However, the concept of a clinically significant tumor introduced initially by Stamey [3] has long arisen. It has being understood as such that injury due to its natural history can compromise the cancer specific survival of the patient. It will be identified for the highest Gleason Score (SG), or by having extra capsular extension or the greater volume. The index lesion is considered to be the area to be treated and should include the clinically significant tumor if it is multifocal, and if there were several significant lesions we would have a single index lesion but

several regions in need of treatment. Initially the entire prostate gland (Whole-gland) was treated with these new energies, as in the case of Cryotherapy or HIFU. After some experience the FT were progressively addressed in a partial or hemi glandular manner. In the high volume centers, the treatment of the index injury in an ultra-focused manner is advocated, it is focused Focal Therapy, but always enough margin (around $9 \mathrm{~mm}$ ) is included to avoid the risk of under treatment. It is important to recognize the location and actual spread of the tumor, which opens a new dilemma [4].

\section{The second dilemma: Location of the tumor}

In this regard, prostate multiparametric magnetic resonance imaging (mpMRI) emerges as the fundamental tool that led to the advancement of these alternatives, constituting the reference method through which the location of the lesion is defined. There are many studies that sought to define the underestimation range of the MRI with respect to the anatomopathological report, being able to determine a correction factor not yet standardized that is around $9 \mathrm{~mm}$ in its entire circumference [4]. We must recognize that, like any dependent operator method, the learning curve is crucial, and although there are training programs, it is difficult to define when someone is sufficiently qualified to detect suspicious areas in a prostate magnetic resonance imaging (prostate MRI).
For the method universalization, reporting standards and recommendations for conducting research studies have been created. As are the ESUR (EAU Section of Urological Research) guidelines of 2012, PIRADS v.1, and the START recommendations in 2013 [5,6]. Subsequently, with the results of the PIRADS v1 experience and in search of a more universal and reproducible standard (independently of the economic and technological level), the PIRADS classification v.2 [7] was created. It is not a consolidated issue, so that specialists from the area are still meeting to define if they should modify the latest version to include new suspected groups or add new sequences to redefine known risk groups. In some years we will probably talk about PIRADS v.3 Regarding diagnostic or confirmatory prostatic biopsy, it is suggested that it should be by fusion with transrectal or transperineal MRI, including directed punctures and systematic or randomized biopsy of no less than 12 punctures, with rigid fusion or visual estimation in case of experienced hands. [1].

\section{The third dilemma: Therapeutic monitoring}

The incorporation of FT has advanced so rapidly that it is not yet established what is the best way to define therapeutic success or failure. The penultimate consortium of experts in FT (2016) [8] was precise in this regard, the results were defined according to different variables, briefly described below. Biochemical Recurrence (BR): In some cases, PSA is used as in radiotherapy treatments, with the Phoenix or ASTRO criteria according to the preference of each center. But we cannot standardize the control method of a whole-gland treatment to that of a focused type of energy, which acts differently in the surrounding tissues. Others consider BR when the NADIR value is not less than $50 \%$ of the pre-treatment PSA [9]. Because of this, in most series they have chosen the biopsy at predefined intervals as the standard of posttreatment evaluation [10]. There was consensus regarding how to define 3 different types of "therapeutic failure".

a. Failure in ablation, when the recurrence is exactly in the area of previous treatment.

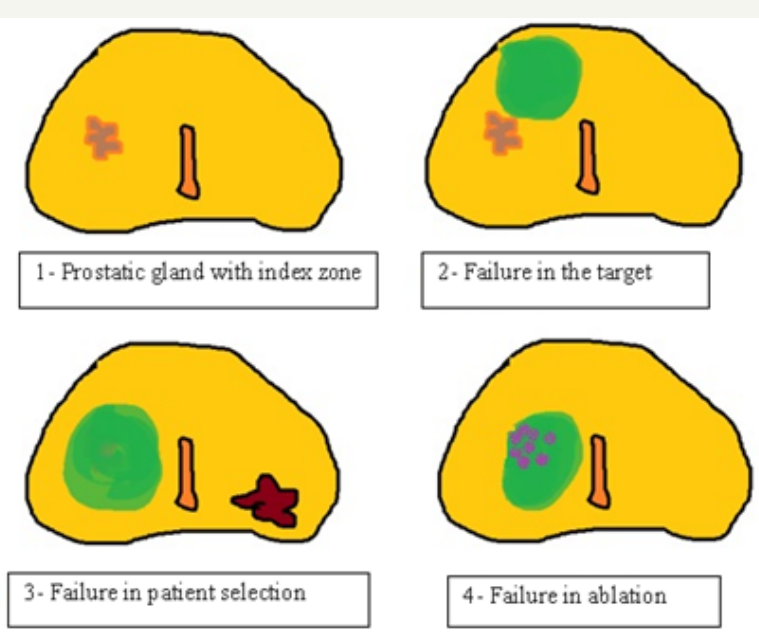

Figure 2: Modalities of therapeutic failure. (In green color treatment area with FT) 
b. Failure in the "target", when we have not applied the energy in the corresponding area.

c. Failure in the selection of the patient, when we are faced with recurrence or early metastases that do not coincide with the risk attributed initially, either because there was another tumor or because it was underestimated (Figure 2). There is great variability in the way to perform the control biopsy, from isolated targeted punctures or the same combined with systematic biopsies. The times between treatment and control biopsy is not yet standardized. Some centers perform the control biopsy at 3 or 6 months and repeat it a year, and others start at 12 months and repeat after 3 years of the procedure. Clearly, this is a great point to standardize to allow future comparisons. Biopsy is an invasive method, with complications risk and not very pleasant for patients, so it is also important to avoid it beyond it is necessary.

The panel of experts also recommends monitoring through $\mathrm{mp}$ MRI. It could be able to observe the appearance of injuries in untreated areas or residual disease. It is recommended not to assign a score of PIRADS in case of suspicious imaging in a previously treated area, but simply to suggest the suspicion of remnant tissue because of an early contrast enhancement in the dynamic study. We wont expect to find that characteristics in an area that should present residual fibrosis. The mp MRI became the tool that defines the area of possible residual disease, to then direct the biopsy and subsequent rescue therapy.

\section{Conclusion}

In summary, the focal therapies are here to stay, and international experience proves it. By our side, we must build a comprehensive knowledge of the new technologies that are available today (mpMRI and targeted fusion-biopsies). Unfortunately, we will face the logistic and economic limitations that arise as a barrier or delay to innovation in our environment.

\section{References}

1. Tay KJ, Scheltema MJ, Ahmed HU, Barret E, Coleman JA, et al. (2017) Patient selection for prostate focal therapy in the era of active surveillance: an International Delphi Consensus Project. Prostate Cancer Prostatic Dis. 20 (3): 294-299.

2. Noguchi M, Stamey TA, McNeal JE, Nolley R (2003) Prognostic factors for multifocal prostate cancer in radical prostatectomy specimens: lack of significance of secondary cancers. J Urol. 170 (2 Pt 1): 459-463.

3. Stamey TA, Freiha FS, McNeal JE, Redwine EA, Whittemore AS, et al. (1993) Localized prostate cancer. Relationship of tumor volume to clinical significance for treatment of prostate cancer. Cancer. 71 (3 Suppl): 933-938.

4. Le Nobin J, Orczyk C, Deng F-M, Melamed J, Rusinek H, et al. (2014) Prostate tumour volumes: evaluation of the agreement between magnetic resonance imaging and histology using novel co-registration software. BJU Int. 114 (6b): E105-E112.

5. Barentsz JO, Richenberg J, Clements R, Choyke P, Verma S, et al. (2012) ESUR prostate MR guidelines 2012. Eur Radiol. 22 (4): 746-757.

6. Moore CM, Kasivisvanathan V, Eggener S, Emberton M, Fütterer JJ, et al. (2013) Standards of reporting for MRI-targeted biopsy studies (START) of the prostate: recommendations from an International Working Group. Eur Urol. 64 (4): 544-552.

7. Barentsz JO, Weinreb JC, Verma S, Thoeny HC, Tempany CM, et al. (2016) Synopsis of the PI-RADS v2 Guidelines for Multiparametric Prostate Magnetic Resonance Imaging and Recommendations for Use. Eur Urol. 69 (1): 41-49.

8. Postema AW, De Reijke TM, Ukimura O, Van den Bos W, Azzouzi AR, et al. (2016) Standardization of definitions in focal therapy of prostate cancer: report from a Delphi consensus project. World J Urol. 34 (10): $1373-1382$.

9. Lambert EH, Bolte K, Masson P, Katz AE (2007) Focal cryosurgery: encouraging health outcomes for unifocal prostate cancer. Urology 69 (6): $1117-1120$

10. Valerio M, Ahmed HU, Emberton M, Lawrentschuk N, Lazzeri M, et al. (2014) The role of focal therapy in the management of localized prostate cancer: a systematic review. Eur Urol 66 (4): 732-751.
Creative Commons Attribution 4.0

International License

For possible submissions Click Here

\section{Submit Article}

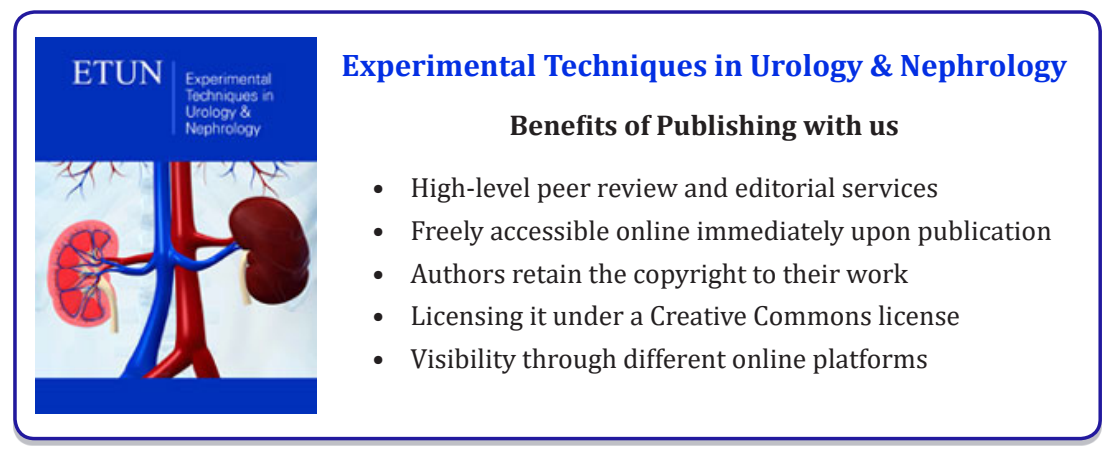

